\title{
A NOVA SISTEMÁTICA DO FUNDO DE GARANTIA APLICADA ÁS RESCISÕES CONTRATUAIS POR EXTINÇÃO DE EMPRESA
}

\author{
Prof. WILSON MAITO STINGLIN \\ Prof. Assistente do Departamento de Direito Privado \\ da Universidade Federal do Paraná.
}

\begin{abstract}
Partindo do pressuposto de que as causas da EXTINÇÃO DA EMPRESA, são decorrentes, predominantemente, da vontade do Empregador, isto é do elemento volitivo, exceção da Força Maior e Culpa recíproca, foram fixados os parâmetros para a pesquisa, partindo dos preceitos doutrinários que serviram de embasamento para a solução de tais questões, procurouse identificar e selecionar cada uma dessas causas extintivas, por entender ser esta a origem da ruptura do pacto laboral. A seguir foi desenvolvido estudo crítico para cada um dos eventos identificados e, afinal, foram selecionadas as normas que proporcionam sustentação legal aos direitos do Empregado, figura esta que, sem qualquer culpa no evento, é atingido diretamente, sofrendo, por conseqüência, o estigma do desemprego.
\end{abstract}

\section{I N TROD U Ç ÃO}

A nova Constituição Federal - C.F. $\left({ }^{11}\right)$ de 5-10-88 preconizou regime jurídico de pessoal, único para todos os trabalhadores regidos pela Consolidação das Leis do Trabalho C.L.T. $\left({ }^{3}\right)$ extingüindo, por via de conseqüência, o antigo regime estabilitário, previsto nos art. 492 a 500, integrantes do Capítulo VII, Título IV, desse diploma legal. Tal medida está corisubstanciada no art. 7, Inciso I, da Constituição Federal C.F. ${ }^{11}$ ) que disciplina como direito dos trabalhadores urbanos e rurais, o que segue:

R. Fac. Direito, Curitiba, a.26, n.26, p.25-46, 1990/91 
Art. $7 .^{\circ}$, Inciso 1 - relação de emprego protegida contra despedida arbitrária ou sem justa causa, nos termos de lei complementar, que preverá indenização compensatória, dentre outros direitos.

Assim entendido, está definitivamente revogado, a partir de 05-10-88, data da promulgação da nova Coristituição Federal C.F. ${ }^{(11}$ ) 0 instituto de ESTABILIDADE, como era concebido pela Consolidação das Leis Trabalhistas - C.L.T. $\left({ }^{3}\right)$ e quo pode ser resumido como sendo um regime jurídico que premiava o desempenho do trabalhador, pelo tempo de serviço em que o mesmo permanecia numa só Empresa, proporcionando-Ihe Garantia no Emprego, uma vez completado o período de 10 (dez) anos de serviço.

Desta forma, uma vez provado o período de 10 (dez) anos de permariência na Empresa, o Empregado adquiria garantia neste emprego, só podendo ser despedido por JUSTA CAUSA, e ainda, desde que a mesma fosse precedida de um inquérito judicial presidido por um Juiz de Direito do Trabalho.

Igualmente alcançados pelo preceito constitucional ora enfocado, foram os que ainda não tinham completado os 10 (dez) anos de serviço exigido para alcançarem o privilégio da ESTA BILIDADE no emprego, cuja situação jurídica era de instabilidade, idêntica a dos empregados sob o regime do Fundo de Garantia por Tempo de Serviço - F.G.T.S. $\left({ }^{4}\right)$, denominados OPTANTES, diferenciados apenas no que diz respeito aos direitos à indenização quando da rescisão dos seus contratos de trabalho, distinções essas que serão abordadas ao longo deste trabalho.

\section{OS REGIMES JURÍDICOS EXISTENTES ATÉ 04-10-88}

Inicialmente é importante ressaltar que os empregados regidos pelo extinto regime estabilitário eram subdivididos em dois tipos de coritratos: os de prazo DETERMINADO e os de prazo INDETERMINADO.

Para os empregados que mantinham contrato por prazo Determinado, quando da extinção da relação de emprego, sem justa causa, eram regulados pelo art. 479 da CONSOLIDAÇÃO DAS 
LEIS DO TRABALHO - C.L.T $\left({ }^{8}\right)$ que previa uma indenização decorrente da ruptura contrátual antes do termo estipulado, da seguinte maneira:

Art. 479 - Nos contratos que tenham termo estipulado, o empregador que, sem justa causa, despedir o empregado será obrigado a pagar-Ihe, a título do inderização, e por metade, a remuneração a que teria direito até o termo do contrato.

É de se registrar que este modelo de indenização, preconizado pelo artigo acima transcrito, só teve vigência até 04-10-88 pois, considerando que a duração máxima dos contratos a prazo determinado é por dois anos, incluída aí, a possibilidade de prorrogação por uma vez, tem-se que, depois da data de 04-10-90 ficou definitivamente revogado o modelo de indenização alí previsto.

Já com relação aos empregados que mantinham contrato de trabalho sem determinação de prazo, ou seja, INDETERMINADO, na ocorrência de rescisão sem justa causa, os trabaIhadores teriam direito a indenização de um mês, por ano trabalhado, sobre a maior remuneração percebida na Empresa (art. 477 C.L.T.), acresoido de mais um ano, pela fração de tempo de serviço igual ou superior a 6 (seis) meses, (art. 478 C.L.T.).

De outra sorte, o modelo vigente para os OPTANTES do Fundo de Garantia por Tempo de Serviço — F.G.T.S. $\left({ }^{6}\right)$, quarido da despedida sem justa causa, determina a liberação, através de autorização, preenchida no próprio Termo de Rescisão, da importância depositada ao longo do contrato de trabalho, pela Empresa, em Banco de sua escolha, à conta do F.G.T.S. e, em nome do Empregado, acrescidos os valores, de juros e correção monetária do período.

Desse total que compreende o principal mais juros e correção monetária, foi fixada multa a ser paga pelo Empregador, no passado, de valor correspondente a um percentual de $10 \%$ (dez por cento), atualmente aumentada em 4 (quatro) vezes, por imperativo constitucional (DT/C.F., art. 18, parágrafo $1 .^{\circ}$ ), 
preceito este, reproduzido no art. 18 , parágrafo $1 .^{\circ}$, da Lei n. ${ }^{\circ}$ 8036/90 - Fundo de Garantia por Tempo de Serviço - F.G.T.S. $\left({ }^{4}\right)$.

Quanto às demais verbas salariais ou indenizatórias, eram mantidos os mesmos direitos para os três modelos existentes, oferecidos pelas normas de então, para todos os empregados do setor privado, fosse qual fosse o regime a que estivessem submetidos.

Quando do rompimento do contrato pela vontade do Empregador isto é, arbitrariamente ou sem justa causa, as indenizações eram fixadas de acordo com o tipo de contrato mantido, isto é, um modelo para indenização para NÃO OPTANTES com prazo determinado; um modelo para NÄO OPTANTES com prazo indeterminado e, finalmente, um modelo para OPTANTES do Fundo de Garantia por Tempo de Serviço.

Embora o presente estudo se destine à análise de eventos ocorridos com 0 trabalhador urbano é interessante registrar 0 fato de que 0 art. $7 .^{\circ}$ da Constituição Federal - C.F. $\left({ }^{11}\right)$ estendeu os direitos destes, aos trabalhadores rurais e que, por causa disso, a lei ordinária vai defrontar-se com sérias dificuldades para regulamentação das duas situações, por ter que dispensar igual tratamento aos dois tipos de trabalhadores que labutam, sabidamente, em situações muito diversas.

Outro fato que merece registro é a citação do art. $7 .^{\circ}$ da Constituição Federal - C.F. $\left({ }^{11}\right)$ já comentado, ao se referir em LEI COMPLEMENTAR para disciplinar a relação de emprego e que até agora, na prática, houve mesmo a utilização de Lei Ordinária, para este fim, como é o caso da Lei $n$. $8036 / 90$, o que, de certa maneira, não se coaduna com o texto constitucional.

\section{O PODER REGULAMENTAR DO PODER EXECUTIVO E SUA IMPORTANNCIA NO DIREITO DO TRARALHO}

Quando uma lei ordinária está em vigência, gravitando no mundo jurídico plena de eficácia, por ser ela de caráter geral e abstrata, na maioria das vezes, necessita de regulamentação com o objetivo de explicitá-la ou complementar o seu entendimento para que possa ser aplicada corretamente. 
Essa tarefa incumbe, é de competência do Poder Executivo que, por meio de DECRETO, procede a regulamentação da norma emanada do Poder Legislativo.

No entanto, há ainda outros órgãos, dentro da estrutura do Poder Executivo, de hierarquia inferior, que também editam normas de procedimento a serem observadas.

Tal fato é de importância para todos os ramos de Direito pois que, além da Norma Maior, editada pelo Poder Legislativo e regulamentada pelo Poder Executivo, há a intervenção de órgãos hierarquicamente inferiores do segundo escalão de governo que, dentro de sua área de competência ou por delegação, editam normas para fixar procedimentos específicos, tendentes à agilização do processo de cumprimento ou execução das normas maiores.

\section{A EXTINTA LEI N. $5107 / 66$ E DEMAIS NORMAS}

Colocado o assunto concernente à complementação da norma maior, em relação ao Direito do Trabalho tem-se que a Lei 5107, de 13 de setembro de 1966, que criou o Fundo de Garantia por Tempo de Serviço - F.G.T.S. $\left({ }^{6}\right)$, entre outras coisas, estabeleceu que, a partir de 01-01-67 o empregador deve recolher, mensalmente, a um Banco de sua escolha, $8 \%$ (oito por cento) do total de sua folha de pagamento de pessoal, separados em duas contas distintas: OPTANTES cuja titularidade da conta é do Empregado e NÃO OPTANTES cujo titular é a própria Empresa e, que todo esse recolhimento, destina-se a financiamento de construções habitacionais e, ainda, que tais contas, rendem juros e correção monetária aos seus titulares.

A seguir, em decorrência do seu poder regulamentar, 0 Poder Executivo editou o decreto n. ${ }^{\circ} 59820 / 66\left({ }^{7}\right)$ fixando os procedimentos necessários à fiel execução do que foi disciplinado pela Lei ordinária.

Esses dois atos aperias, não foram suficientes para a correta interpretação e aplicação da norma substantiva. Por isso veio se unir aos dois diplomas legais, a POS/02-78, do Banco Nacional de Habitação - B.N.H. $\left({ }^{12}\right)$, disciplinando procedi- 
mentos, pertinentes à Movimentação do Fundo, pelos Empregados, Empregadores e outros, fixando os eventos em que tais verbas podem ser movimentadas.

Outros atos mais, relativos ao tema foram editados ao longo dos tempos, para orientação e fixação de procedimentos, ou pelo Poder Legislativo, complementado por regulamentação do Poder Executivo, tendo em vista acomodar situações novas, não previstas inicialmente, mas que, na prática, vieram a ocorrer.

Porém, o que importa ressaltar é que todo esse universo de normas elaboradas com base na lei ordinária, pelos órgãos da Administração do Poder Executivo, objetivando a regulamentação de um determinado tema, desde que ocorra a EDIÇÃO de uma nova Lei Ordinária, portanto Norma Maior, disciplinando o tema de forma diversa ao que estava, até então, resulta em REVOGAÇÃO que pode ser expressa ou tácita da Lei anterior e, por via de conseqüência, também, na revogação de todas as demais normas hierarquicamente inferiores, inclusive os atos editados pelo Poder Executivo, em tudo o que não se identifique com o novo modelo proposto e em vigor.

Tal priricípio de direito, está consubstanciado no que dispõe o artigo $2 .{ }^{\circ}$, parágrafo $1 .{ }^{\circ}$, do Decreto-Lei n. ${ }^{\circ} 4657 / 42$ Lei de Introdução ao Código Civil, que assim disciplina:

Art. 2, parágrafo $10^{\circ}$ - A Lei posterior revoga a anterior quando expressamente o declare, quando seja com ela incompatível ou quando regule inteiramente a matéria de que tratava a Lei anterior.

A constatação da existência de uma nova Lei ordinária, modificarido inteiramente o F.G.T.S., vem causando certa intranquilidade e apreensão a todos àqueles que foram atingidos pela nova medida e que, na realidade, são constituídos por toda a força de trabalho do País, desde que regidos pela Consolidação das Leis Trabalhistas - C.L.T. $\left({ }^{8}\right)$ uma vez que a nova ordem constitucional extinguiu o antigo regime ESTABILITÁRIO, obrigando seus antigos tutelados a se submeterem, também, e sem opção, a partir de 05-10-88, ao novo regime jurídico imposto, por ser o único existente, disciplinado, atual- 
mente, pela Lei 8036 , de 11 de ma:o de $1990\left(^{4}\right)$ que veio substituir a Lei 7839 , de 12-10-89 $\left({ }^{5}\right)$, ambas versando sobre o mesmo tema, conforme se verá a seguir.

\subsection{A Lei n. 7839 , de 18-10-1989 $\left({ }^{5}\right)$}

A Lei em epígrafe veio disciplinar o Fundo de Garantia por Tempo de Serviço - F.G.T.S. $\left({ }^{5}\right)$, de forma inteiramente nova, desde a sua estrutura organizacional, seu funcionamento, redistribuindo competência aos novos órgãos, criados para gerir o seu patrimônio e, também, em consonância com o disposto no texto constitucional, previu a inclusão dos ex-estabilitários ao novo regime legal, fixando ainda, os direitos relativos ao tempo de serviço anterior a 5-10-88, prestados sob o regime jurídico diverso do instituto pela Lei em questão. A mesma Lei, em seu artigo 30, expressamente revogou a Lei n. ${ }^{\circ} . .$. $5107 / 66\left(^{6}\right)$ e todas as demais disposições em contrário. Foi regulamentada pelo Decreto n..$^{\circ} 98813$, de 10 de janeiro do $1990\left({ }^{9}\right)$.

Estranhamente, a Lei n. $7839 / 89\left(^{5}\right)$ teve período de vigência pouco significativo pois foi revogada pela Lei $n .^{\circ} 8036$ de 11 de maio de 1990, portanto, menos de sete meses depois de editada. Curiosamente a Lei n. $8036 / 90$ veio repetindo todo o que já estava previsto na Lei anterior e do cotejamento entre as duas normas de direito, percebe-se que nesta, todos os assuntos tratados pela outra norma foram mantidos integralmente, o que se observa daí, tratar-se de mera reedição da primeira, sem qualquer alteração significativa, quanto aos aspectos fundamentais abordados.

\subsection{A LEI 8036, de 11 de maío de $1990\left({ }^{4}\right)$}

Atualmente a Lei em epígrafe é a única norma que disciplina o Fundo de Garantia por Tempo de Serviço — FGTS $\left({ }^{4}\right)$ como regime único para os empregados vinculados à C.L.T., desde 05-10-88, por decorrência de imperativo Constitucional que, como já foi dito, aboliu o regime estabilitário.

Mas que fazer com aqueles empregados que estavam sob a égide do regime estabilitário vigente até 04-10-88 e que conviviam em plena harmonia com o regime do Fundo? 
A Lei n. ${ }^{\circ} 8036 / 90$ traz a resposta, disciplinando em seu art. 14, o que segue:

Art. 14 - Fica ressalvado o direito adquirido dos trabalhadores que, a data da promulgação da Constituição Federal de 1988, já tinham o direito à estabilidade no emprego, nos termos do capítulo $\mathrm{V}$, do Título IV, da CLT.

Dessa forma ficou resguardado o direito daqueles que antes de 05-10-88 estavam com mais de 10 (dez) anos de serviços prestados à mesma Empresa, sob o regime estabilitário.

Como o enfoque deste trabalho é voltado para as conseqüências resultantes da aplicação dos preceitos aqui discutidos quando da rescisão dos Contratos de Trabalho, tem-se a questionar que, em se tratando a Estabilidade funcional de real garantia de emprego para o trabalhador, esta garantia, reconhecida pelo art. 14, da Lei em epígrafe, deve ser obstáculo intransponivel ao Empregador que queira promover a ruptura do contrato de trabalho com empregado seu que tiver mais de 10 (dez) anos de serviço, à data da promulgação da Constituição Federal, mesmo que este empregado, atualmente, se encontre sob o regime jurídico único do Fundo de Garantia eis que, por DIREITO ADQUIRIDO, não poderá ser dispensado a não ser por Justa Causa e, ainda, desde que esta seja precedida por Inquérito Judicial.

No entanto, há uma exceção à regra geral: trata-se de casos de extinção da Empresa ou qualquer de seu estabelecimentos ou supressão de qualquer de suas atividades. Em qualquer desses casos, justifica-se a ruptura contratual de estáveis, eis que, em desaparecendo o objeto do pacto laboral, que é a prestação de serviços pelo empregado, não se justifica a manutenção do Contrato de Traba!ho.

A extinção da Empresa, tanto por vontade do Empregador quanto por motivo alheio a esta mesma vontade (força maior ou fato do príncipe) podem ocorrer no curso do contrato de emprego. Os vários casos serão oportunamente comentados, na continuação. 
Dessa forma entendido, só é permissivel a ruptura contratual de empregados que tenham mais de 10 (dez) anos de serviços prestados à mesma Empresa, em data de 05-10-88, dentro dos estritos motivos apontados neste tópico, por força de Direito Adquirido.

\subsubsection{Parágrafo $1 .^{\circ}$ artigo 14 , Lei $8036 / 90$}

A leitura superficial do parágrafo em epígrafe, muito embora, a primeira vista, dê a impressão de abrigar somente casos dos que adquiriram estabilidade no emprego, na realidade tutela também, os empregados com tempo inferior aos 10 (dez) anos, exigidos para aquisição da estabilidade, porém, sob o mesmo regime. É o que se infere da interpretação do parágrafo que assim estabelece:

Parágrafo $10^{\circ}$ - O tempo do trabalhador não optante do F.G.T.S. anterior a 05-10-88, em caso de rescisão sem justa causa, pelo empregador, reger-se-á pelos dispositivos constantes dos artigos 477, 478 e 497 da C.L.T.

Os dois primeiros artigos de n. 477 e 478 , da CLT, referem-se a casos de indenização de empregados que ainda não completaram os 10 (dez) anos exigidos para aquisição da estabilidade. Dessa forma entendido é direito adquirido também dos empregados NÃO OPTANTES, até 05-10-88, portanto, com tempo inferior a 10 (dez) anos, sem estabilidade.

O modelo previsto na CLT para empregado nessas condições é de indenização correspondente a maior remuneração percebida na Empresa, a cada ano de serviço prestado, acrescentando-se mais um ano, por fração igual ou superior a 6 (seis) meses de serviço.

Completando o entendimento deste tópico, está previsto indenização em dobro, nos casos em que seja permitida a ruptura do contrato de trabalho dos estáveis, conforme dispõe o artigo 497-CLT, ou ainda, nos termos do artigo 496-CLT, que prevê a transformação, pelo Juiz do feito, dos casos de reintegração, em indenização. 
É, s.m.j., o melhor entendimento do artigo 14 , da lei n. ${ }^{\circ}$ $8036 / 90$, em seu parágrafo primeiro. Para completá-lo resta, tão somente, levar em consideração de que esse tempo do serviço esteja intocado, isto é, não utilizado por qualquer motivo como se verá, a seguir, no comentário aos parágrafos seguintes do mesmo artigo ora enfocado.

\subsubsection{Parágrafo 2, art. 14 - Lei 8036/90}

O artigo 14 , da Lei n. $8036 / 90$ contém outros parágrafos destinados a proporcionar, com relação ao tempo de serviço prestado à Empresa, antes de 05-10-88 sob o regime de NÃO OPTANTE, algumas soluções a seguir analisadas:

Diz o parágrafo 2:

O tempo anterior à atual Constituição poderá ser transacionado entre o Empregador e Empregado, respeitado o limite de sessenta por cento da indenização prevista.

A aplicação do disposto riesse parágrafo é para os casos de NÃO OPTANTES, estáveis ou não estáveis à data de 04-10-88, iśto é, tanto aplica-se a transação para os que são estáve:s, com mais de 10 (dez) anos de serviço, quanto àqueles que ainda não tinham atingido aquela marca, na data fatal.

Pode-se utilizar a expressão ALIENAÇÃO ou VENDA do tempo de serviço anterior à nova Constituição Federal, que terá como base para o cálculo da indenização prevista, a maior remuneração percebida pelo empregado, por ario de serviço prestado à Empresa, acrescido de ma:s um ano, pela fração igual ou superior a seis meses.

Este parágrafo reproduz integralmente o que tinha sido previsto quando da implantação do F.G.T.S. Naquela oportunidade, a partir de 1967, a Lei da época liberou a transação às partes interessadas com a mesma proteção de $60 \%$ (sessenta por cento) mínimo de indenização. apenas aos que detinham o direito à estabil:dade, deixando liberdade quanto aos demais empregados, não tendo estes, qualquer direito ao mínimo garantido aos estáveis. 
Atualmente, a proteção da Lei, a um mínimo de sessenta por cento do que é devido de indenização, está prevista também aos não estáveis, credores de tempo a ser transacionado, anterior a 1988 .

Uma vez concluído o acordo entre às partes, dentro dos limites mínimos exigidos para a efetivação da transação, o Empregado perde a Estabilidade, se a tinha, podendo, daí em diante, ser despedido sem justa causa pois que, a transação, importa também, na perda da estabilidade aos que a detinham, na qualidade de NÃO OPTANTES.

Deve ser acrescentado que, embora possa ser dispensado sem justa causa, o empregado continua protegido pelos dispositivos do F.G.T.S., regime este que obrigatoriamente se filiou, a partir de 05-10-88.

Portanto, embora possa o Empregador despedir arbitrariamente o empregado, fica sujeito ao pagamento de uma multa correspondente a quarenta por cento do valor total depositado no Banco, acrescido de juros e correção monetária, a partir da data da filiação do empregado ao Fundo de Garantia por Tempo de Serviço - F.G.T.S.

\subsubsection{Parágrafo $3 .^{\circ}$, Artigo 14 - Lei 8036/90}

Este dispositivo prevê a possibilidade do Empregador depositar, na conta do Empregado, a indenização do tempo de serviço como Não Optante, da forma seguinte:

Parágrafo $3 .^{\circ}-E$ f́ facultado ao Empregador desobrigar-se da responsabilidade de indenização relativa ao tempo de serviço anterior à opção, depositando na conta vinculada do trabalhador, até o último dia útil do mês previsto em Lei para o pagamento do salário, o valor correspondente à indenização, aplicando-se ao depósito, no que couber, todas as disposições desta Lei.

Observa-se do enunciado, alguns elementos de muita importância para os que gozam de estabilidade sob o regime anterior: A Empresa, em assim agindo, desobriga-se da res- 
ponsabilidade da indenização relativa ao tempo de serviço anterior. Assim, mesmo que haja o depósito permitido, na conta do Empregado, relativo à indenização do tempo anterior, não afeta o Instituto da Estabilidade, isto é, o simples depósito não deve produzir efeitos quanto ao direito do empregado à garantia de emprego que o mesmo tem, não podendo, dessa forma, haver despedimento sem justa causa pois que, tal depósito, refere-se exclusivamente à satisfação pecuniária, não atingindo o Instituto da Estabilidade que deve permanecer incólume.

Já com relação aos não estáveis que tinham menos de 10 (dez) anos de serviço à época, a dispensa sem justa causa poderá ocorrer normalmente, independentemente de depósito antecipado na conta deste Empregado, aberta a partir de 05-10-88, por imposição legal.

Se a Empresa usar da faculdade permitida em Lei e depositar a indenização devida na nova conta do Empregado, o valor desta certamente aumentará. Ademais, o Empregador, para esta operação terá que usar dinheiro de seu caixa pois a Lei não contempla a hipótese de liberação da conta Empresa/Emregado para tais casos em que a relação de emprego continua.

Por todos esses motivos é de se observar que tal parágrafo, pelos evidentes inconvenientes, se torne letra morta, isto é, nunca venha a ser usado pelo Empregador.

Para melhor entendimento do que foi até agora comentado é interessante desenvolver um exemplo concreto dos efeitos, para o Empregador, em usar ou não a faculdade permitida para proceder o depósito antecipado, pelo que dispõe o parágrafo em epígrafe, no curso do contrato de trabalho, partindo do seguinte enunciado:

\section{EX EMPLO}

Um empregado foi despedido Sem Justa Causa, em data de 05-10-1991. Foi o mesmo admitiido na Empresa em 05-10-1985, na condição de não optante. Recebe atualmente Cr\$ 60.000,00 (sessenta mil cruzeiros) mensais de salário. O Empregador depositou a importância de Cr\$180.000,00 (cento e oitenta mil 
cruzeiros), correspondentes a antecipação de sua indenização, pelo tempo de (três) anos de serviço, na condição de Não Optante, em sua nova conta, aberta em 05-10-88. Na data da despedida, ocorrida em 05-10-91, a nova conta do Empregado acusava o valor de Cr\$ $360.000,00$ (trezentos esessenta mil cruzeiros) mais juros e correção monetária creditados pelo Banco, de depósitos efetuados a partir de 5-10-88, acrescido do valor da antecipação depositada.

Com as informações ordenadas no parágrafo anterior, pode-se proceder o acerto das contas do empregado que ficam assim dispostas:

\begin{aligned} depósitos regulares em 3 anos & $=180.000,00 \\$ depósitos para acerto antecipado & $=180.000,00 \\$ juros incidentes no período & $=180.000,00 \\$ multa de 40\% sobre as parcelas acima & $=180.000,00 \\$\cline { 2 - 2 } & $=644.000,00\end{aligned}$

No entanto, se for considerada a possibilidade do Empregador não ter depositado antecipadamente, no curso do contrato, a indenização devida pelo tempo de 3 (três) anos na condição de NÃO OPTANTE, quando da ruptura do contrato, o acerto final de contas fica desta maneira:

$$
\begin{array}{ccr}
\text { depósitos regulares de } 3 \text { anos } & =180.000,00 \\
\text { multa de } 40 \% \text { sobre a parcela acima } & =72.000,00 \\
\text { Indenização p/acerto de N.O (13/12) } & =\frac{195.000,00}{} \\
\text { Total indenizado } & 447.000,00
\end{array}
$$

Cotejando o resultado das duas contas realizadas, verifica-se que a primeira delas acusa prejuízo do Empregador de Cr\$197.000,00, que corresponde a $30 \%$ do total, sem contar os juros e correção monetária do valor depositado na conta do Empregado, para acerto de seu tempo de serviço, como Não Optante, pois que, se fosse depositado em poupança em nome do Empregador, deste seriam os rendimentos representados por juros e correção monetária. 
Vale a pena repetir que, além dos prejuízos demonstrados com o primeiro exemplo acima, tais depósitos efetivados à conta dos empregados estáveis, não resulta em perda do trabalhador da GARANTIA DE EMPREGO que subsistirá mesmo com 0 depósito do valor desta indenização e que, além disso, rião se previu. na Lei $8036 / 90$, a liberação da verba, pelo F.G.T.S., ao Empregador, da conta Empresa/Empregado, só admitida quando da aposentadoria ou ruptura contratual de caráter excepcional de empregados estáveis.

\subsubsection{Parágrafo $4 .^{\circ}$, Art. 14, Lei $8036 / 90$}

O parágrafo em epígrafe é reprodução do que disciplinava também a lei $n .^{\circ} 5958 / 73$, editada ao tempo do regime militar de 1964, sobre o F.G.T.S. porém aquela, resguardando interesses dos Empregadores, limitou a possibilidade de opção retroativa ao F.G.T.S., à concordância prévia do Empregador.

Este novo dispositivo não exige a intervenção da Empresa para que se opere a opção por vontade do Empregado disciplinando o tema em seu art. 14, parágrafo $4 .{ }^{\circ}$, nos seguintes termos:

Parágrafo $4 .^{\circ}$ - Os trabalhadores poderão, a qualquer momento optar pelo F.G.T.S., com efeito retroativo a $1 .^{\circ}$ janeiro de 1967, ou à data de sua admissão, quando posterior àquela.

O Fundo de Garantia por Tempo de Serviço - F.G.T.S. $\left({ }^{4}\right)$ foi idealizado para financiar o sistema nacional de habitação, objetivo este que se mantém. A principal fonte de arrecadação do Fundo são os depósitos que o Empregador faz, em Banco de sua escolha, mensalmente, do correspondente a $8 \%$ (oito por cento) do total de sua folha de pagamento de pessoal. à conta do Fundo de Garantia por Tempo de Serviço, em duas contas distiritas:

Para os que à época optavam pelo F.G.T.S. (lei 5107/66) eram denominados Optantes e a conta mantida no Banco era individualizada em nome do Empregado, quer dizer que este era o seu titular, porém com vinculação à Empresa que, em 
alguns casos, incumbia autorizar a liberação dos depósitos, em favor do Empregado, como ocorria, por exemplo, nas despedidas sem justa causa. O mesmo procedimento está consagrado pela rovas normas que disciplinam o F.G.T.S. (8036/90).

Porém, aos empregados que preferiram permanecer no regime estabilitário, denominado de NÃO OPTANTES, até 04-10-88, o recolhimento ao Banco era efetuado em outra conta, cuja titularidade é da Empresa depositante.

As duas contas rendem juros e correção monetária, de acordo com o fixado em Lei e a movimentação das mesmas, depende de certos acontecimentos, disciplinados por normas próprias, como, por exemplo quando da ruptura do pacto laboral em que, comprovado o pagamento da indenização devida, na hipótese de despedida sem justa causa, o Empregador levanta o total depositado na conta Empresa/Empregado, pertinente aos depósitos efetuados em nome do Empregado não optante, liberação esta, de competência do Conselho de Curadores do F.G.T.S.

Outro exemplo de levantamento do Fundo de Garantia, pela Empresa é a hipótese de aposentadoria voluntária do Empregado Não Optante, cuja decretação, pelo antigo Instituto Nacional de Previdência Social - I.N.P.S., proporcionava a liberação, para a Empresa, do valor total dos depósitos em Banco, já acrescidos de juros e correção monetária.

Outros exemplos ainda poderiam ser aqui arrolados, todos apontando para a assertiva de que os valores depositados pelo Empregador, ao longo do tempo, na conta Empresa/Empregado, à conta do Fundo, constituem ativos diferidos da Empresa que serão incorporados ao seu patrimônio, sempre que evento permissível ocorra.

No entanto, pelo parágrafo $4 .^{\circ}$ reproduzido, a OPÇÃO RETROATIVA, aqui colocada como faculdade do empregado de a utilizar, sem a intervenção da vontade do Empregador, tal como está disciplinada, permite a transferência de todo o numerário depositado na conta Empresa/Empregado, relativa a situação de NÃO OPTANTE do Empregado, para a nova conta, cuja titularidade passa a pertencer a este último.

R. Fac. Direito, Curitiba, a.26, n.26, p.25-46, 1990/91 
Por outro lado, em função desta transferência de numerário para a nova conta do Empregado, no caso do Empregador resolver dispensá-lo arbitrariamente, sem justa causa, deverá pagar os $40 \%$ de multa, também sobre o valor da transferência, com aumento significativo do seu encargo.

Uma derradeira observação a ser feita quanto ao artigo 14 e seus parágrafos é a de que, em todos os casos ali previstos é mantida a relação de emprego entre as partes. O que se altera é unicamente o direito do Empregado ao tempo de serviço prestado à Empresa, até 04-10-88.

\section{MOVIMENTAÇÃO DA CONTA EM QUE É TITULAR O EMPREGADOR}

Relativamente ao tempo de serviço anterior a 05-10-88, a corita do F.G.T.S., de titularidade da Empresa deverá ser movimentada em caso de Extinção do Contrato de Trabalho mediante ou de indenização antecipada, paga ao Empregado Não Optante ou decorrido o prazo prescricional para reclamação dos direitos por parte do Empregado e, em ambos os casos, mediante comprovação das duas situações, pelo Empregador, conforme se depreende do art. 19, inciso I e II, da Lei ora enfocada.

Como não está prevista qualquer outra forma de levantamento das importâncias depositadas à conta Empresa/Empregado, fica dificultada a utilização da faculdade do Empregador, prevista no parágrafo $3 .^{\circ}$, do artigo 14 , como citado anteriormente.

\section{HIPÓTESES DE MOVIMENTAÇÃO DA CONTA PELO EMPREGADO}

Por ser o F.G.T.S. o único regime jurídico de pessoal, desde a data da promulgação da Constituição Federal de 5-10-88, a indenização fixada para todos os Empregados se resume no que respeita a ruptura do pacto laboral, ao que dispõe o artigo 18 e seus parágrafos que prevêem as seguintes hipóteses: 
a) Indenização devida pelo Empregador a $40 \%$ do valor dos depósitos do F.G.T.S. depositados ao longo do tempo em que o trabalhador prestou serviços à Empresa;

b) Indenização devida pelo Empregador quando do rompimento do contrato de trabalho por culpa recíproca, ou força maior, desde que reconhecida pela justiça do Trabalho, correspondente a uma multa de $20 \%$ do valor dos depósitos do F.G.T.S., durante o tempo em que o empregado trabalhou na Empresa.

As legislações anteriores, já revogadas, previam, além dos casos apontados acima, com os mesmos percentuais, outros casos mais, como o de extinção de Empresas, de forma total ou parcial, como, ainda, de quaisquer de seus Estabelecimentos, Filiais ou Agências, ou ainda, a supressão de parte de suas atividades, com o seguinte detalhamento:

A extinção da Empresa pode resultar de acontecimentos que vão, desde a vontade do Empregador (elemento volitivo), que não deseja continuar com o seu ramo de atividade, incluindo-se aqui, casos de dificuldades financeiras da Empresa, que resultam em Concordata preventiva, ou podem resultar também de outros motivos alheios a esta vontade e, neste caso, diversos desdobramentos se impõe, como a decretação da Falência por seu Juízo próprio:

A extinção, por imposição de autoridade pública ao cancelar concessão para exploração de serviços públicos ou desapropriação desses mesmos serviços.

Extinção, por decorrência de força maior por causas que podem ser de ordem natural como por exemplo inundação ou terremoto, ou por fatores humanos como sabotagem e negligência.

Em qualquer dos casos apontados, por desaparecer o objeto do pacto laboral que é a prestação de serviços, a extinção de Empresa resulta também, na extinção do Contrato de Trabalho, por falta deste mesmo objeto e, dependente dos motivos que deram causa à extinção, a Lei anterior (5107/66), obri- 
gava o Empregador ao pagamento de indenização de maior ou menor valor, ao Empregado atingido com a dispensa.

Esse ônus imposto ao Empregador, pelo rompimento do contrato de trabalho era fruto do entendimento de que o Empregado, por não participar dos lucros eventuais da Empresa, recolhidos apenas pelo Empregador, não devia, como contrapartida, sofrer os prejuízos resultantes ou não da vontade do Empregador que seria o único a participar dos riscos normais do empreendimento empresarial e, por isso mesmo, suportar o ônus da indenização do Empregado.

Esse entendimento nada mais é que a aplicação da Teoria do Risco, defendida por Duguit, ampliada que foi pela Doutrina alemã para a Teoria do Risco da Empresa, citada por Mascaro do NASCIMENTO $\left({ }^{1}\right)$ e, adotada para estes casos, pelo Direito do Trabalho nacional, aplicado que são, nos seguintes eventos:

a) na extinção da Empresa, sem força maior, devidas serão, integralmente, as indenizações trabaIhistas. E.N.44 - Tribunal Superior do Trabalho - T.S.T. $\left({ }^{10}\right)$.

b) paralizando-se definitivamente a Empresa por ato que impossibilite a continuação da atividade, ao Empregado é assegurada a indenização integral, que será paga pelo Governo responsável pela paralização. C.L.T. - Art. $485\left({ }^{8}\right)$

c) Quando cessar a atividade da Empresa, por morte do Empregador, o Empregado terá direito à ser indenizado integralmente. C.L.T. - Art. $485\left({ }^{8}\right)$.

d) a Extinção da Empresa, em virtude da ocorrência de Força Maior, bem como na extinção de um de seus estabelecimentos, será devida a indenização pela metade. (C.L.T. Art. 502).

Todas as regras estão consubstanciadas na Consolidação das Leis do Trabalho - C.L.T. $\left({ }^{8}\right)$ e davam suporte ao modelo indenizatório porém, por causa da extinção deste regime jurídico pela Constituição Federal de 1988, tornaram-se inóquas, não aplicáveis. 
Assim, pelos motivos acima expostos, a partir de 5-10-88, pelo atual regime fixado pela lei $8036 / 90$, não mais cabe qualquer indenização ao Empregado pela extinção da Empresa, exceção, apenas, a casos de Força Maior que lá estão contemplados com multa de $20 \%$ do valor total depositados no F.G.T.S.

É interessante ressaltar que a posição do Legislador em relação à Força Maior, ao prever multa de $20 \%$, pela Extinção da Empresa em que resulte a rescisão do Contrato de TrabaIho, conduz ao raciocínio de que, pelo menos os casos de Extinção da Empresa, por ato de vontade do Empregador, desde que resultem extinção do contrato de trabalho, devem ser considerados como ato de "despedida sem justa causa" e, por conseqüência, imposta a multa correspondente. Porém, nada disto está previsto em Lei, expressamente.

Quanto aos demais casos de extinção enumerados anteriormente, a Lei também é omissa, prevendo, tão somente, a liberação do Fundo ao Empregado, sem qualquer indenização cabível, constituindo-se numa válvula de escape aos que desejarem fraudar os direitos do empregado. Condição perigosa, omissão na Lei, muito perigosa mesmo, aos interesses dos empregados.

A solução para esta situação pode ser perfeitamente encontrada, se se conseguir, junto ao Corpo Legislativo, a inclusão do dispositivo que preveja solução para estes casos, quando da elaboração de Lei Complementar, preconizada pelo artigo $7 .^{\circ}$, inciso I, da Constituição Federal - C.F. $\left({ }^{11}\right)$. Para que isto ocorra será necessária a manifestação de todos os órgãos de proteção aos interesses dos trabalhadores, como sindicatos e associações para, junto aos srs. Parlamentares, insistirem na edição de normas que prevejam soluções para as hipóteses aqui aventadas, porém omissas na atual legislação do F.G.T.S.

\section{DOS CONTRATOS A PRAZO DETERMINADO}

Uma outra questão também de omissão da nova legislação do F.G.T.S., é relativa a existência dos Contratos por Prazo 
Determinado, ao lado dos Contratos por Prazo Indeterminado e que na vigência do anterior regime jurídico era disciplinado pelo que dispunha 0 art. 479 da C.L.T., nos seguintes termos:

Artigo 479 - Nos contratos que tenham termo estipulado o Empregador que, sem justa causa despedir o empregado será obrigado a pagar-lhe, a título de indenização, e por metade, a remuneração a que teria direito até o termo do contrato.

A norma acima era aplicável apenas aos Não Optantes ao Fundo de Garantia por Tempo de Serviço. Posteriormente, o Legislador, sensível ao prejuizo que, para casos idênticos sofria o Optante do Fundo, que tinha como único direito, o levantamento do Fundo de Garantia, equacionou o problema, resolvendo-o através do que dispõe o art. 30 , em seu parágrafo $3 .^{\circ}$, do Decreto n. 59820/66, nos termos que seguem:

Art. 30, parágrafo $3 .^{\circ}$ - Na rescisão antecipada do Contrato de Trabalho por Prazo Determinado, de iniciativa da Empresa, esta pagará ao empregado a eventual diferença entre o valor da indenização a eventual diferença entre o valor da indenização prevista no artigo 479, da Consolidação das Leis do Trabalho e o saldo de sua conta vinculada.

Assim, em se considerando que, em nenhum momento, a Lei n. ${ }^{\circ}$ 8036/90 faz distinção entre Contratos a Prazo Determinado e Prazo Indeterminado, até mesmo na questão de reconhecimento de direitos adquiridos dos trabalhadores e relativos ao tempo de serviço anterior à atual Constituição Federal é de se observar, por tais evidências, que a forma de indenização para a ruptura dos Contratos por Prazo Determinado, antecipadamente e por iniciativa da Empresa, reger-se-á por um único modelo, qual seja o do levantamento da conta do F.G.T.S., dos depósitos efetuados até a data da ruptura do pacto laboral, acrescidos de juros e correção monetária e. deste total, será calculada uma multa correspondente a $40 \%$, quando se tratar de despedida imotivada, o que é muito pouco em relação ao que estava fixado pela anterior legislação. 
Esta igualdade de tratamento entre os dois tipos de con trato de trabalho, sejam elas de prazo determinado ou prazo Indeterminado é regulada unicamente pela Lei 8036/90 e faz desaparecer, por absoluta incompatibilidade, o modelo preconizado pelo artigo 479 da C.L.T., combinado com o artigo 30, parágrafo $3 .^{\circ}$, do Decreto $59820 / 66$, tornando-os def:nitivamente revogados.

Algumas soluções estão serido aventadas por autorizados autores trabalhistas como é o caso de Gabriel SAAD $\left({ }^{2}\right)$ que, em seus comentários à nova Lei $8036 / 90$, que regulamenta o F.G.T.S., propõe, relativamente à ruptura antecipada por decisão do Empregador, que a Empresa deposite o F.G.T.S. relativo ao tempo de serviço que falta para o cumprimento integral do contrato de trabalho e, em seguida, seja calculado cs $40 \%$ correspondentes à multa fixada, em função da arbitrariedade do Empregador.

\section{C O N C L U S Ã O}

Pelos aspectos abordados e do cotejamento das duas logislações, anterior e a nova, chega-se a conclusão de que, na maioria dos casos, houve substaricial perda dos direitos dos Empregados que se constituem, vale dizer, na parte economicamente mais fraca da relação de emprego.

De sorte que, vale repetir, é de fundamental importância que o Sindicato dos Empregados de todas as categorias, tontem sensibilizar os srs. Parlamentares no sentido de que estes, quando da elaboração e votação da Lei Complementar sobre a matéria enfocada, iricluam, pelo menos, os mesmos direitos dos empregados, existentes anteriormente, nos atuais casos de ruptura contratual imotivada, sob o regime da Consolidação das Leis do Trabalho, restabelecendo, na ordem jurídica, àqueles mínimos direitos que já tinham sido conquistados pelos trabalhadores, sabe-se bem, a quantas penas.

\section{ABSTRACT}

Departing from the supposition that the causes of the extinction of a legal entity is a consequence of a preponderantly decision of the volitive wil of the owner except in case of 
force majeure or reciprocal fault, were established parameters for the research, starting from doctrinaires precepts for the solution of such questions, looking forward to identify and relate one of such extinguishing causes on the assumption that these causes are the origin of the breach of the working contract. In the sequence appears a critical study for each one the identified events and at last were selected norms which sustain the employee legal rights. The employee, having no fault in the extinguishing of the legal entinty is directly for consequently he will lost his job.

\section{REFERENCIAS BIBLIOGRÁFICAS}

1 NASCIMENTO, Amauri Mascaro. Iniciação ao Direito do Trabalho. 14 ed. 2 Tiragem, São Paulo : LTr, 1990. 510 p.

2 SAAD, Eduardo Gabriel. Consolidação das Leis do Trabalho Comentada. 23 ed., São Paulo: LTr, 1990. 654 p.

3 CONSOLIDAÇÃO das Leis do Trabalho anotada. 5.ed., São Paulo: Mapa Fiscal, 1989. 802 p.

4 BRASIL. Lei 8036, de 11 de maio de 1990. Dispõe sobre o Fundo de Serviço e dá outras providências. D.O.U., Brasília, 14 de maio de 1990.

5 BRASIL. Lei 7839, de 12 de outubro de 1989. Dispõe sobre o Fundo de Garantia por Tempo de Serviço e dá outras providências. D.O.U., Brasília, 12 de outubro de 1989.

6 BRASIL. Lei 5107, de 13 de setembro de 1966. Dispõe sobre o Fundo de Garantia por Tempo de Serviço e dá outras providências. D.O.U., Brasilia, 14 de set. 1966.

7 BRASIL. Decreto 59820, de 21 de dezembro de 1966. Regulamenta a Lei 5107, de 13 de setembro de 1966. D.O.U., Brasília, 27 dez. 1966.

8 OLIVEIRA, Juarez de. Consolidação das Leis Trabalhistas : C.L.T. 12 ed., São Paulo : Saraiva, 1990. 599 p.

9 BRASIL. Decreto 98813, de 10 de janeiro de 1990. Regulamenta a Lei 7839/89. D.O.U., Brasília, 11 jan. 1990.

10 BRASIL. Enunciado n. 44 - Regimento Interno do Tribunal Superior do Trabalho : T S T Sem publicação no D.O.

11 BRASIL. Constituição da República Federativa do Brasil. 1988, Brasília, Senado Federal, 1988. 299 p.

12 BRASIL. Portaria Ordem de Serviço n.॰ POS/02/78. Banco Nacional de Habitação - B.N.H. 1978. Sem publicação no D.O. 